\title{
Comment: Gender inequality in work-family balance
}

Oriel Sullivan

University of Oxford

e-mail: oriel.sullivan@sociology.ox.ac.uk 


\section{Comment: Gender inequality in work-family balance}

Recent highly publicized statistics from the Pew Research Centre show that there is a gender pay gap of $18 \%$ in the US ${ }^{1}$, despite half a century of women moving into paid employment in increasing numbers. As I show, gender inequality in pay is intricately linked to gender inequality in work-family balance. In keeping with the spotlight of this issue on 'labour', I focus on the 'who does what' question of work-family balance; in particular the unequal gender division of paid and unpaid work, and the effect of this inequality on women. The extent and cross-national scope of this inequality is a pressing matter on an international level ${ }^{2}$, and it will require both innovative policy approaches and significant shifts in gender attitudes to amend it.

\section{The unequal gender division of labour}

At the Centre for Time Use Research at the University of Oxford, inequalities in the gendered use of time is at the heart of our research. Using our multi-national archive of time use diaries $^{3}$ we are able to document 50-year trends, from the 1960s through to the first decade of the $21^{\text {st }}$ Century, across 24 countries, in the average amounts of time that working-age women and men spend in paid and unpaid work 4 . Figure 1 (upper two graphs) shows that, while the overall time that women spend in unpaid work (including all forms of family care) has decreased substantially on a cross-national basis over 50 years, the time that men spend doing such work has generally increased, though less impressively. It is often said, correctly, that equalizing trends mainly reflect a reduction in women's contributions rather than an increase in men's, but it is also well recognised that men's overall contributions have 
increased - albeit slowly - on a cross-national basis over the last half-century ${ }^{5}$. Despite this movement in the direction of greater gender equality, the trend lines for women and men do not meet-this reflects the persistent and pervasive disproportionate load of unpaid work and care still undertaken by women.

Trends in paid work time (lower 2 graphs) to some extent mirror the trends in unpaid work time, with a general decline in men's average paid work time. Women's overall paid work time, by contrast, either rises, or, in some countries, decreases somewhat. On average, across this large sample of countries and surveys, women still do over $60 \%$ of the unpaid work, and just about $40 \%$ of the paid. 
Figure 1. Women and men's average minutes per day in unpaid and paid work: populations aged 20-59

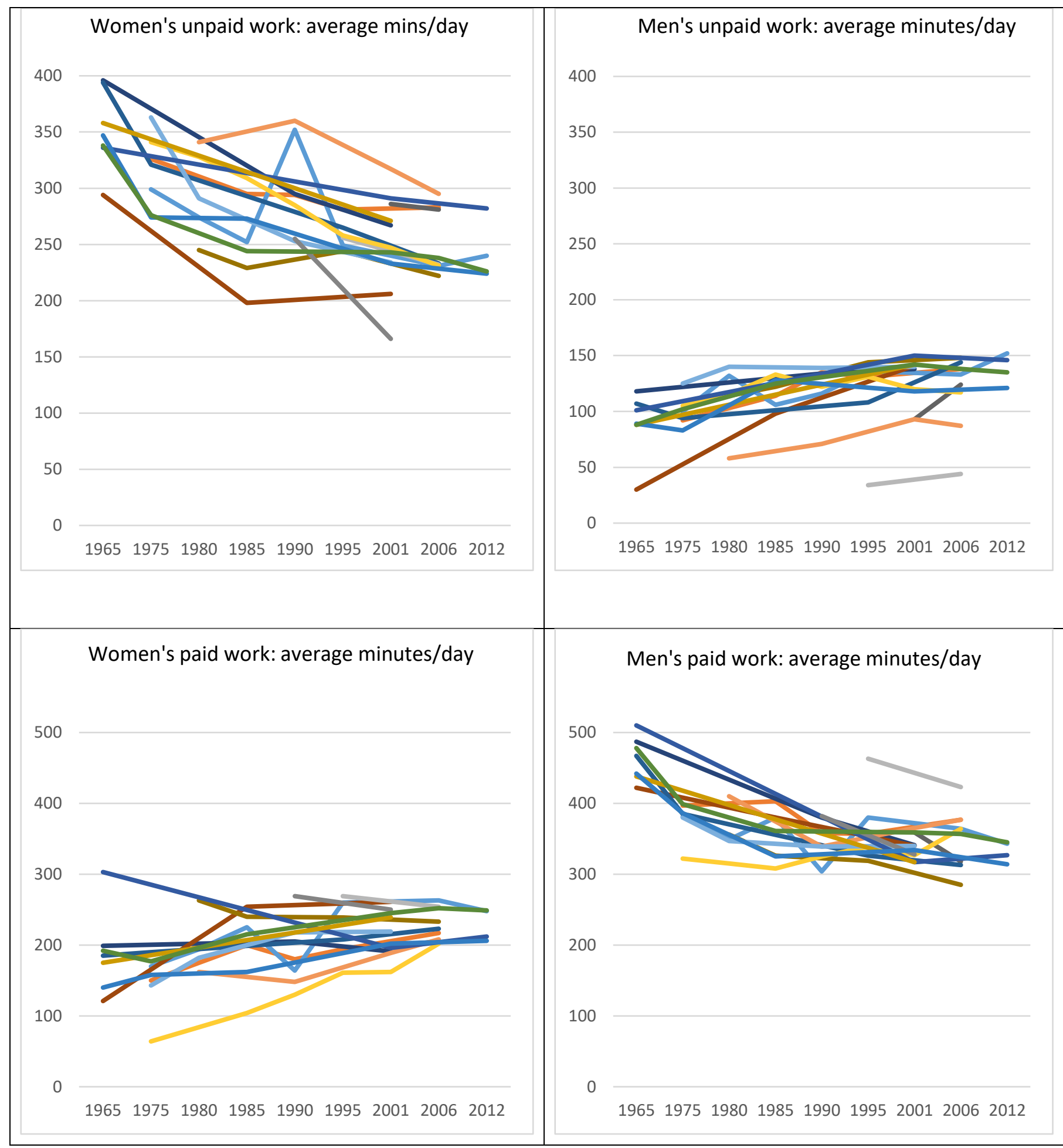

Note: As surveys were conducted cross-nationally at different dates, the horizontal axis dates show the mid-points of the periods during which surveys took place. Country legend:

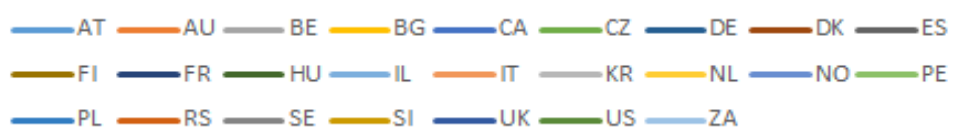


We can step back from the overall statistics to illustrate more at a more human level some of the processes that play out in the development of these inequalities in work-family balance over the course of a single individual's life, using a simple 'vignette'. We start with a girl's initial gender socialization. Her parents' domestic practices can be expected at least partly to reflect a previous generation's gender attitudes and expectations. These are likely to be already out of step with current conditions because of the slow and imperfect impact of policy changes, as well as her parents' socialization within ideologies and conventions inherited from their own parents. The educational and employment opportunities for girls in most societies over the latter part of the 20th century were significantly greater than those that were available to their mothers, although their brothers' options were, in most cases, not so different from those of their fathers. Therefore, if and when the girl forms a heterosexual partnership, her paid employment, combined with both her and her partner's inherited expectations of gendered responsibilities and behaviours, leads to an unfair accumulation of paid and unpaid work on her shoulders. This accumulation is increased if and when she has children. She experiences this in the form of various specific sorts of disadvantages: in reduced life chances in relation to leisure time; in more limited choices regarding family formation options; in restrictions on career development; or all of these in combination.

At the same time, she is involved in social interactions relating to these issues of work-family balance, particularly in the context of her interaction with her partner. In the face of the slow and often incomplete adaptation of husbands to their wives' paid employment, women's choices are limited: to suffer in silence while continuing to do the bulk of the housework, to 
exit either the labour market or the marriage, or to attempt to negotiate change within the context of her marital relationship, thus facing potential conflict ${ }^{6}$.

The significance of these processes, and the pace at which they play out depends, of course, on specific historical and cultural contingencies, including the consistency and commitment with which policy changes are advanced, the speed and enthusiasm with which such changes are adopted and translated into behaviour, and the general pace of change at the level of ideology.

But how does this map onto gender inequalities in the overall balance of paid and unpaid work on the population level? Returning to the time use data, if we calculate the proportion of all work that is done by working-age women (that is, including both paid and unpaid work) across different countries and plot this over time, we arrive at Figure 2 . We see a reasonably constant clustering of the national trend lines around the $50 \%$ level, plus or minus $3 \%$, depending on country context. In other words, when we sum paid and unpaid work together, it appears that women and men do, on the average, a relatively equal amount of overall work. 
Figure 2. Women's proportion of all work: population aged 20-59

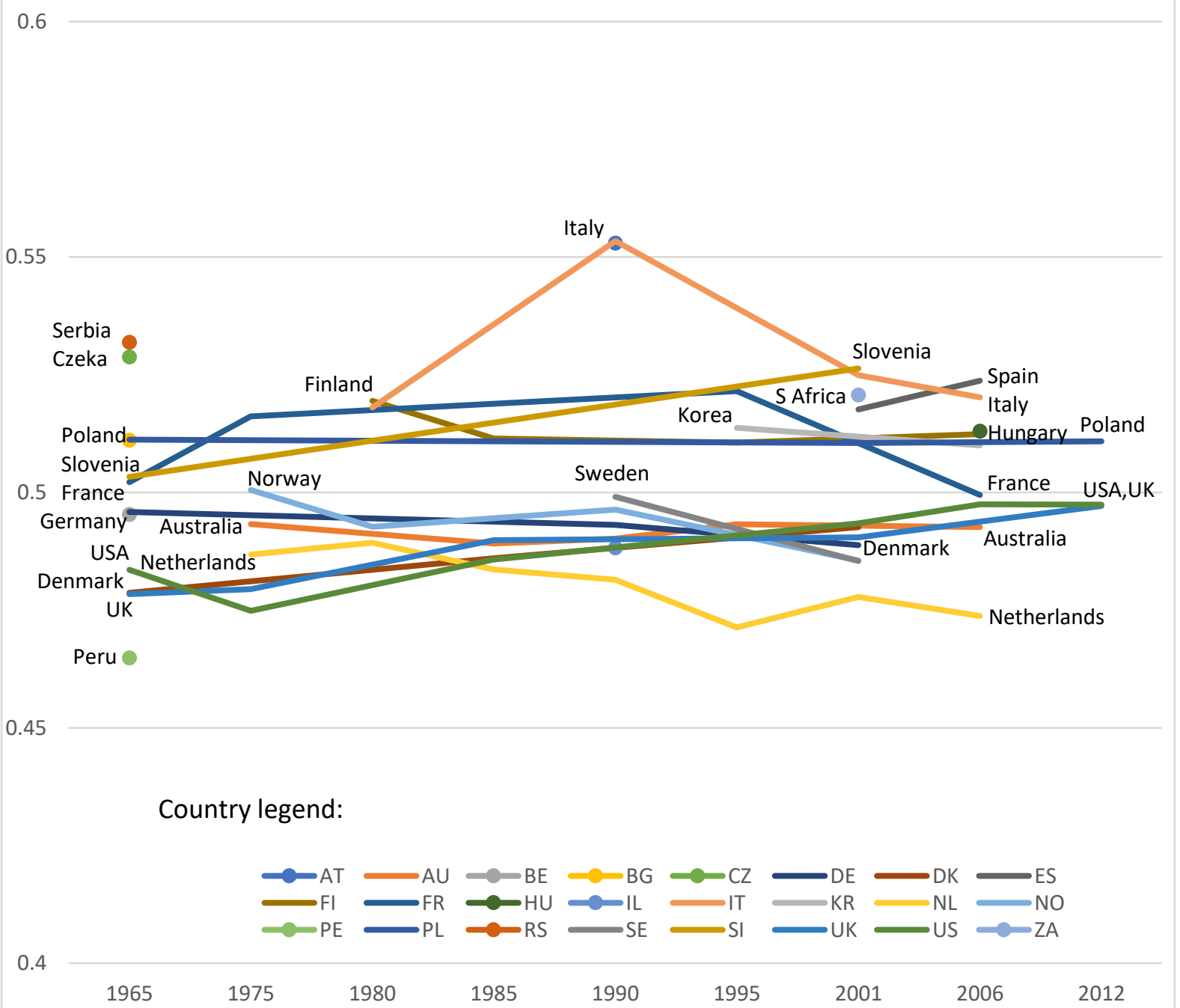

Note: As surveys were conducted cross-nationally at different dates, the horizontal axis dates show the mid-points of the periods during which surveys took place. Countries with a single survey only are indicated by a single dot.

However, the appearance of relative gender balance here is not all it seems, because these overall averages of time spent in paid and unpaid work disguise some fundamental and critical inequalities. 
Firstly, as I alluded to in the introduction, there is an intimate connection between unequal time and unequal money. The fact that men do substantially more paid work, and women do substantially more unpaid work (including family care) has important knock-on consequences for inequality in earnings. The extra time in employment for men translates directly into extra human capital (meaning extra skills and experience, leading to greater employability and promotability). This extra human capital constitutes a major element in the explanation of the ubiquitous and still-substantial gender gap in wage rates.

Secondly, specific subgroups of the population tend to do more total work than others. In the UK in 2014-15 the hardest working groups were partnered mothers and fathers combining full-time employment with childcare, followed by employed single parents. In both cases women in these groups spent slightly longer in total work than men. The biggest gender gap was between non-employed partnered mothers (a large group including full-time stay-athome carers) and equivalent fathers (a relatively small group comprising the unemployed and some stay-at-home carers) $)^{7}$. This is related to the gender 'leisure gap', meaning that women on average, and some groups of women in particular, enjoy less leisure time than men ${ }^{8}$.

Thirdly, not all time is equal. Consistently, research shows that women not only do more unpaid work, but that this unpaid work is likely to involve multitasking, in particular, doing child care along with other household tasks ${ }^{9}$. Women are also still likely to be regarded as responsible for the management of what goes on in the household in terms of child care, household shopping, and core housework (even when it is not them who actually does these tasks). The continued responsibility for family work involving multitasking and the complex management and scheduling of activities has been shown to create 'hot-spots' of time pressure for women ${ }^{10}$. 
These factors; gender inequality in work and leisure time, and the particularly intensive nature of women's time, contribute to the fact that women overwhelmingly report that they feel more rushed than men - a consistent finding from the most recent UK (2014-15) time use survey. In results from that survey, the differences between women and men in their reports of feeling 'always rushed for time' by far outstrip differences measured according to socioeconomic status, or the time spent using digital technologies ${ }^{11}$.

\section{What can be done?}

The challenge is to redress gender inequality in the division of labour, and the gender ideologies that underpin this inequality. Actions that can promote greater equality, and ease the time pressure that women experience, span several levels: from government policy measures to the actions of social movements in influencing attitudes to gender and labour. Although there are significant differences between countries in these things, some general suggestions may nonetheless be made.

In terms of government policies, what is required is commitment to the implementation of measures in support of genuine work-family flexibility, including the statutory reduction of working hours ${ }^{12}$. This would permit couples to stagger their hours of paid work in order to care for their children or other dependents, reducing the need for one parent - usually the woman - to stay home or reduce their hours of paid work. There is evidence that shorter, more flexible working practices and greater diversity are what working millennials want to see in their workplaces ${ }^{13}$.

Equally important is the introduction of high-quality, easily available and affordable early child care facilities. Women and men should be able to return to full-time employment without suffering the penalty of having to bear expensive private child care costs or 
experiencing the guilt of having to leave children for long periods in poorly-funded daycare. Policies should be targeted at enabling an easier return to employment for both partners, on a gender-level playing field, well before their children reach school age. In countries where quality care is both available and affordable, leaving young children in these facilities is the norm (indeed in interviews with new parents in Norway being conducted by one of my DPhil students it is regarded as a positive: both enjoyable and stimulating for children's social development). In countries where they are not, there is inevitably pressure on one parent - in practice almost always the woman - either to remain at home herself over a period of several years in order to care for children, or to return to limited part-time work, or to rely on child care assistance from family members (usually other women).

The establishment of meaningful periods of take-it-or-leave-it paternity leave has also proved effective in transferring care time to fathers. In countries where dedicated father leave has been introduced - most notably in Iceland, where fathers and mothers get 3 months each of non-transferable leave, take-up of the full 3 months by fathers is as high as $65 \%^{14}$. Men who stay home to care for children not only spend more time in childcare, they also do more housework ${ }^{15}$. In addition, the experience of the Nordic countries shows that, once fathers are visible, out and about with prams and pushchairs in the playgrounds, dropin centres and the streets, changes in hearts and minds start to happen.

The combination of policies that permit employed fathers to spend more (paid) time caring for their children with those that provide early public childcare are part of why, according to the World Economic Forum's Global Gender Gap Index, the Scandinavian countries are consistently the best countries in which to be a woman. 
Even with such a transformation in the policy environment, though, a sea-change is unlikely to happen without simultaneous changes in the ideology of traditional masculinity and associated workplace expectations that underpin the gender division of labour. On the one hand the notion that "real" men don't do "feminine" things like care, or housework must be combated. These conceptions have proved far harder to shift than the opposite idea that women can do things that were traditionally thought of as "men's work". Related to this is the challenge posed by traditional workplace management cultures and expectations. Patriarchal management culture praises dedication to the job - construed as working long fixed hours, but also being constantly available, with work at all times taking priority over family. Men who fail to conform to this expectation are regarded, like women, as less reliable and less promotable ${ }^{16}$. Contrast this to the family-friendly attitude displayed by some Norwegian companies in my DPhil student's research: parents, both men and women, refer to workplaces that allow shorter or flexible hours for parents, that express sympathy when sick children require them to take time off, and accept that work can be made up from home when necessary.

\section{Some reasons for hope?}

Three things suggest that there may be cause for hope for the future. The first is the indication of slow but positive changes in attitudes about work-family gender equality, particularly among younger cohorts. An analysis of International Social Survey Programme attitude data showed that, while there was some evidence for a slowing in certain countries (particularly the United States and Britain), men and women's attitudes regarding gender equality continue to converge in the direction of greater egalitarianism ${ }^{17}$. However, it may be that in those countries where the revolution in women's paid work began relatively early we have reached a situation where continued movement in the direction of greater gender 
equality cannot take place without more profund changes occurring in the wider structural, ideological and policy context.

Secondly, and relatedly, there is an ongoing increase cross-nationally in the time that fathers are spending with their children. Time-use data show that U.S. parents, both men and women, have substantially increased their time investment in childcare of all kinds over the past few decades ${ }^{18}$. Recent research focusing on differences between educational groups and types of childcare shows that these increases have been most notable among more highly educated mothers and fathers, and in childcare activities that promote children's opportunities for learning ${ }^{19}$. These increases are also present cross-nationally across a range of developed countries ${ }^{20}$.

Finally, there is the experience of Scandinavian countries, where the trend in the gender division of housework and care continues in the direction of greater gender egalitarianism, and is indeed approaching equality between women and men. For example, in Sweden in 2010 (the most recent Swedish time-use survey), women's share of routine housework time was down to $56 \%$ from $64 \%$ in 1990 . Their share of childcare time was $58 \%$, down from $65 \%$ in $1990^{21}$. These ongoing processes of change in response to both concerted policy efforts and egalitarian normative gender ideologies suggest that where political willingness is implemented in relevant policies, and where gender equality has long been regarded as a social goal, the process of gender convergence in family work and care can continue.

Social movements, such as the women's movement of the 1960s and 1970s, and, more recently, the outcry caused by the continuing gender pay gap (see \#PayMeToo), can have enormous influence here. They can have a powerful impact on increasing awareness about existing inequalities and the pressing need for measures to address them. With sufficient 
proactive support, the sorts of changes I have described may prove be persistent enough over the long term to dissolve the foundations of existing structures of inequality.

\section{Acknowledgements}

The writing of this commentary was supported by the Economic and Social Research Council (Collecting New Time Use Resources, ES/L011662/1) and the European Research Council (Social Change and Everyday Life, 339703).

\footnotetext{
${ }^{1}$ Graf, N., Brown, A. \& Patten, E. Pew Research Centre: Factank series (April 9 2018).

${ }^{2}$ Gender inequalities in work-life balance is one of the key deliverables of the European Pillar for Social Rights: http://ec.europa.eu/social/main.jsp?langld=en\&catld=1226
${ }^{3}$ The data referred to - a substantial archive of time use diaries that have been harmonised for comparative analysis - can be accessed at https:/timeuse.org. Countries were selected on the basis of their data quality.

${ }^{4}$ Some similar but larger-scale figures may be found in Gershuny, J. Centre for Time Use Research Working Paper (February 2018).

${ }^{5}$ Bianchi, Suzanne M., Liana C. Sayer, Melissa A. Milkie and John P. Robinson. Social Forces 91, 55-63 (2012).

${ }^{6}$ Gershuny, J., Bittman, M., \& Brice, J. Journal of Marriage and Family 67, 656-665 (2005).

${ }^{7}$ Sullivan, O. \& Altintas, E. In J. Gershuny and O. Sullivan (Eds.) On Time: Half a Century of UK Daily Life Ch. 5 (Penguin Books, 2019 forthcoming).

${ }^{8}$ Sevilla, A., Gimenez-Nadal, J. I. \& Gershuny, J. Demography 49, 939-964 (2012).

${ }_{9}^{9}$ Sullivan, O. and Gershuny, J. Social Science Research 42, 1311-1324 (2013).

${ }^{10}$ Southerton D. \& Tomlinson M. The Sociological Review 53, 215-239 (2005).

${ }^{11}$ Sullivan, O. \& Gershuny, J. Sociology 52, 20-38 (2018).

${ }^{12}$ Fraser, N. Political Theory 22, $591-618$ (1994).

${ }^{13} 2018$ Deloitte Millennial Survey: www.deloitte.com/MillennialSurvey. (Findings are based on the views of more than 10,000 millennials questioned across 36 countries). 
${ }^{14}$ Eydal, G. B. \& Gíslason, I. V. International Network on Leave Policies and Research Iceland Country Report (2017).

${ }^{15}$ Chesley, N. \& Flood, S. Journal of Marriage and Family 79, 511-534 (2017).

${ }^{16}$ Haas, L., Hwang, P. \& Russell, G. (eds.) Organizational Change and Gender Equity: International Perspectives on Fathers and Mothers at the Workplace (Sage, 2000).

${ }^{17}$ Braun, M., \& Scott, J. In M. Haller, R. Jowell, \& T. W. Smith (Eds.), The International Social Survey Programme, 1984-2009: Charting the Globe pp. 358-377. (Routledge, 2009).

${ }^{18}$ Bianchi, S. M., Robinson, J. P., \& Milkie, M. A. Changing Rhythms of American Family Life. (Russell Sage Foundation, 2006).

${ }^{19}$ Altintas, E. Journal of Marriage and Family 78, 26-42 (2015).

${ }^{20}$ Gauthier, A., Smeeding, T., \& Furstenberg, F. Population and Development Review 30, 647 - 671 (2004).

${ }^{21}$ Pailhé, A., Solaz, A., \& Stanfors, M. Paper prepared for the workshop "Caregiving responsibilities across the life course: An international perspective". Lund May 31 - June 1 (2017). 